\title{
A Web Application Exhibiting Parking Guidance using Smart Sensor Networks
}

\author{
B. Sivakumar, B. Sai Srinivas, V. Ritvik Reddy
}

\begin{abstract}
Smart parking is the digital approach to the modern-day parking problems. This project presents a new approach to the parking problems in our country in which we use ultrasonic sensors to detect the unoccupied places inside the parking area. This data is frequently captured and updated onto a real time cloud database. From that database we fetch the details of the parking area and present it to the end customer in the form of a web base application. This application will show the end customer where are the unoccupied slots are located and the path to that unoccupied space is presented onto the User Interface so that the user can park his car in a very limited amount of time.
\end{abstract}

Keywords: Smart parking System, Ultrasonic sensors, Cloud, path display

\section{INTRODUCTION}

Due to the huge increment with the quantity of newly enlisted automobiles demonstrated unmistakably with the insights gave by the Bureau of Road and Transport, more than $2,75,000$ vehicles in the year 2018 , with $2,52,354$ to be the count in the year 2017 compared to 96,000 in the year 2007. This makes a drastic increase of $160.4 \%$ in the span of 10 years. This calls for a productive and smart parking system to save time and effort for all the large institutions like malls, colleges, companies, etc. Stopping issues are normal in most significant urban areas. The restricted accessibility to park one's automobile brings about traffic blockage, air contamination, and driver dissatisfaction. The cost to park in public places nowadays is skyrocketing, with the time taken to locate an unoccupied space in the parking area makes it just more expensive. Moreover, the security staff taking care of this parking have very little knowledge about how to clear the gridlocks that occur inside the parking lot. An effective way for parking management is needed to ensure free-flowing traffic in the parking lot and to save a lot of precious time. This is a method to ensure the driver gets a parking space in the parking lot using ultrasonic sensors to detect the vacant parking spaces and the web application will guide the driver to the parking space using a heuristic approach.

\section{LITERATURE SURVEY}

Revised Manuscript Received on April 27, 2020.

* Correspondence Author

Dr. B. Sivakumar*,

Associate Professor, Department of CSE,

KTR Campus, SRM IST Chennai, India svakumb2@srmist.edu.in

B. Sai Srinivas,Student, Department of CSE, KTR Campus, SRM IST Chennai, India buddisai_buddi@srmuniv.edu.in

V. Ritvik Reddy, Student, Department of CSE, KTR Campus, SRM IST Chennai, India ritvik_narayan@srmuniv.edu.in

(C) The Authors. Published by Blue Eyes Intelligence Engineering and Sciences Publication (BEIESP). This is an open access article under the CC BY-NC-ND license (http://creativecommons.org/licenses/by-nc-nd/4.0/)
The previous system is not well known as over a few decades back the vehicles were very less on the streets and one had no problem in getting a vacant space for the parking. During these times drivers had it simple, to park their vehicles in a vacant space near the place they want to go. These are the times when the population was less and even less vehicles on the streets as the people could not afford these vehicles and the fuel used. But now the vehicles have increased tenfold and maintaining all these vehicles in a cramped space like a parking lot is a tedious job. The primary outlook of the system corresponds to the fact that drivers are having a very hard time finding an unoccupied place in the parking area. Loads of time with useful energy gets wasted in just finding a simple unoccupied place in the parking area. This thus builds more fuel consumption of the automobile. Parking fare is increased due to lots of waiting, leading to driver frustration and dissatisfaction. The present system consisted of individuals coming to an institution with vehicles asking the security for a vacancy, as they cannot be aware of vacancies in the vast parking space. The individual now relies on the fact that he gets a free parking space when he enters, or else relies on the other security to guide the way to his vacancy in the parking space. This may be feasible if a few cars approach the institution, but the situation in these times have changed. A large number of vehicles approach the institution at the same time, handling all of them is a tedious process. When the individual takes the parking token his time for the parking gets started and if the individual takes a lot of time just to park his vehicle than spending his time in the institution his parking fare increases considerably. The manpower directed to this is the security staff which are there to direct the drivers to their parking spaces, they are not optimal as they themselves do not know where the vacant spaces are present in the parking space and their directions may confuse the driver even more in finding a parking space. This manpower used can be directed to better work like safeguarding the institution or vehicle protection, etc. The system consists of a lot of loopholes and lagging and requires more time as it is done manually. Be that as it may, this is the reality of the parking system in our society and it needs to be changed to cope up with the tremendous increase of vehicles on the road in these times. The analysis of literature survey on the various ways to approach the parking problems in various cities led to diverse conclusions. Regarding the detection phase we can conclude that different sensors can be utilized for the identification of the unoccupied places within the parking area IR Sensing Elements, Optical, Magnetic, etc. but one that stands out is the Ultrasonic Sensor. This sensor is very cheap as compared to other sensors and is readily available in the market.

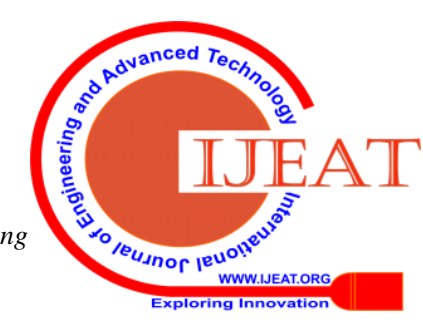


It is easily programmable to calculate distances which can be used to identify the unoccupied places within the parking area. Coming towards display mechanism stated in the above methodologies altogether have a very limited range to the display provided to the user. The display system in the above mostly consists of showing the user how many vacant spaces are available in the parking lot using led lights. This is not enough as the user still does not know where in the parking lot these vacant spaces are located. An effective display of the path should be given to the users so that they can follow that path and reach their parking space swiftly.

\section{PROPOSED SYSTEM}

A well-engineered apt Parking System is the digital approach to deal with most of the parking issues present in the institutions. Smart Parking Systems will have a largescale impact on a vast range of institutions. This parking system that we are proposing is a wholesome, start to finish arrangement that combines a system of sensors, present and live portals with a powerful and reliable cloud-server platform. Unendingly versatile, the excellence of our framework lies in the easy to understand dashboard which empowers clients to oversee and examine occasions and data, just as enabling clients to distinguish slots and translate information. The Smart Parking System offers a scope of sensors to suit the necessities of various parking spaces.
These powerful and adaptable gadgets screen parking areas and transfer live status data to Cloud Database. The Smart Park framework includes in-ground vehicle location sensors, which are introduced per every slot and connected up to a system of Wi-Fi which thus feed ongoing information into our Cloud Database stage. When executed, talented professionals can deal with the supporting needs of their establishment utilizing the simple display that the Cloud Database dashboard gives. The web interface of the parking system can display real-time information around space availability and car park capacity, as well as providing directions to encourage traffic flow.

The pathing which is specified in the web interface will guide the user to their destination comfortably. This pathing is one of the crucial components of any parking system as the shortest path is calculated using a heuristic algorithm and is exhibited onto the web application. The Web utilization of SPS is a complex, incredible and imaginative online help stage that accumulates and forms data. The Smart Parking System is the key requirement to make smarter and better cities for the future.

\section{SYSTEM ARCHITECTURE}
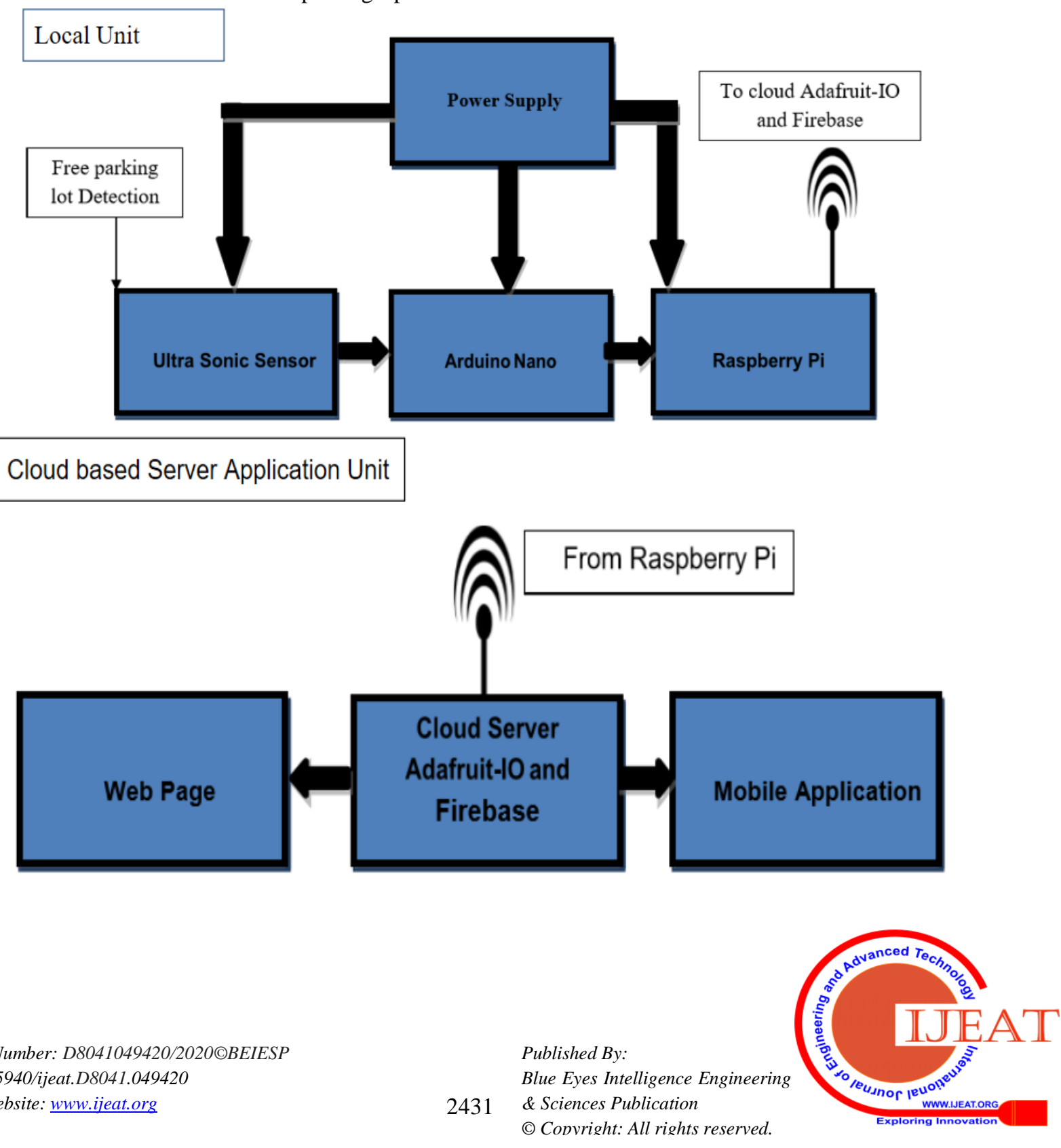
Model diagrams

\section{Parking Management System}
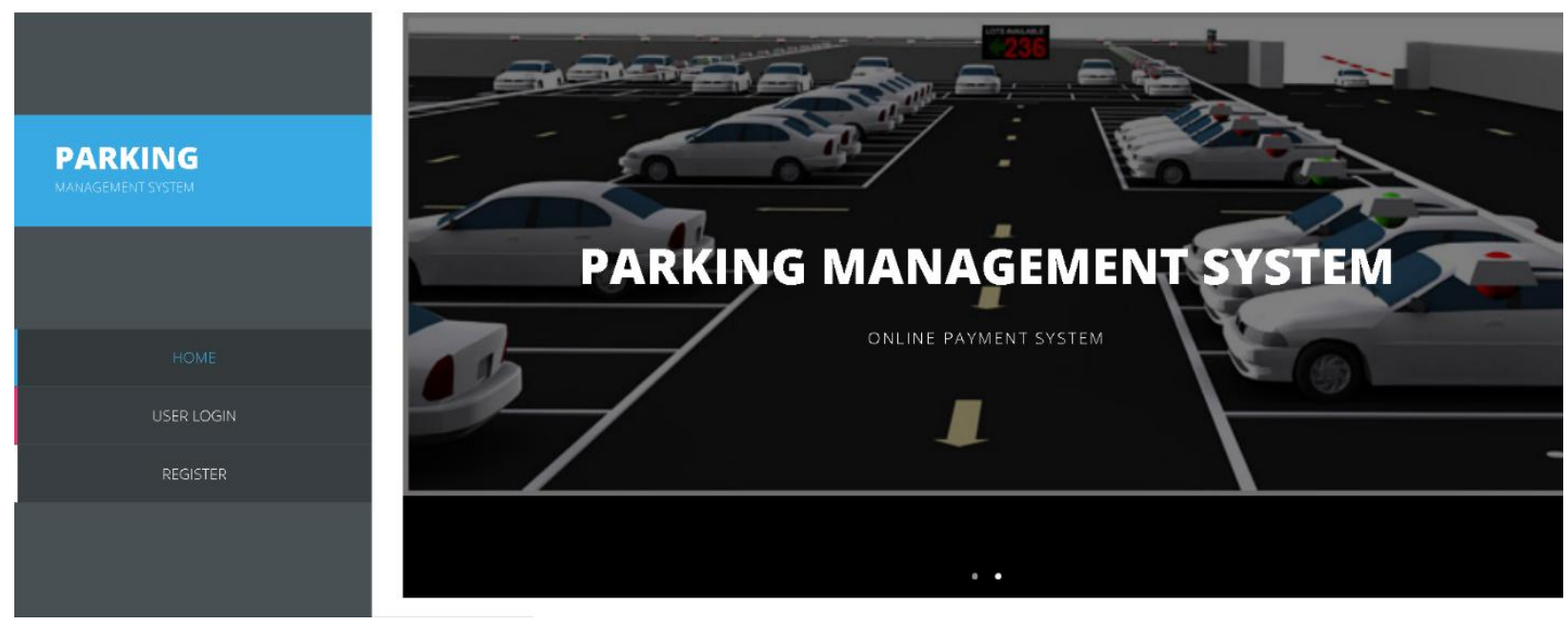

Figure 1:-Web Application Interface

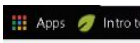

\section{Parking $\mathrm{N}$ \\ it System}

\section{Recharge Slot Booking Booked Details Change Password Logout}

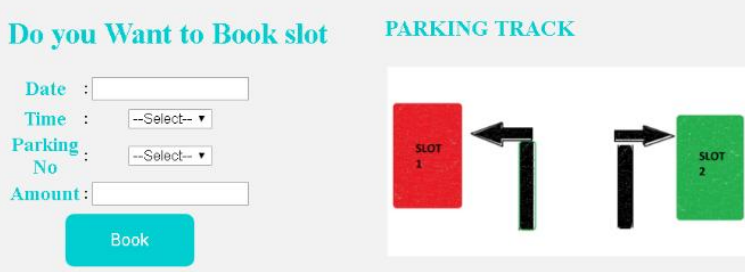

Figure 2:-Slot Booking Through the Web Application

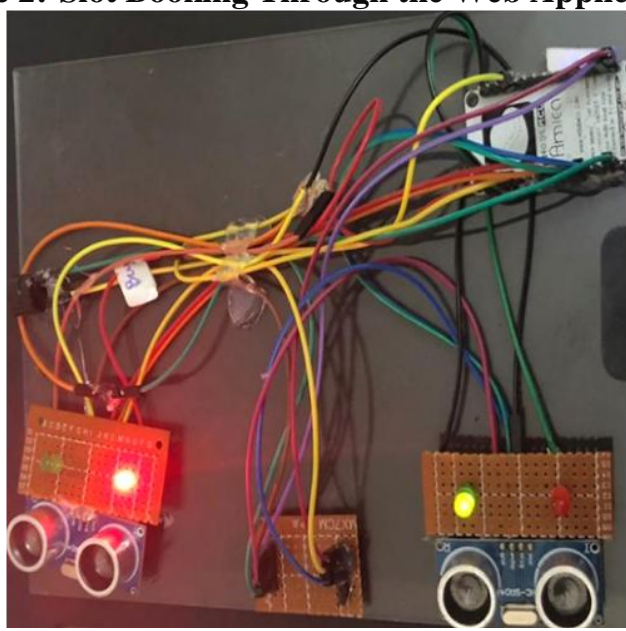

Figure 3:-Slot Booking gets reflected in the Hardware Component

Retrieval Number: D8041049420/2020@BEIESP DOI: 10.35940/ijeat.D8041.049420

\section{Published By:}

Blue Eyes Intelligence Engineering

\& Sciences Publication

(C) Convriaht: All riahts reserved.

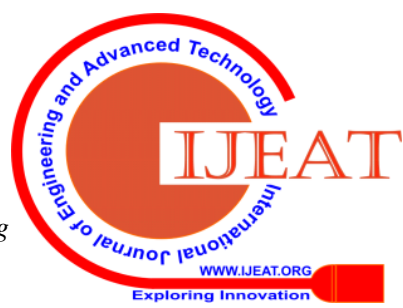




\section{RESULTS AND DISCUSSION}

The objective of this System is to be reliable and costeffective. With this idea the following the following results are obtained and discussed below:

- The Ultrasonic sensors are more apt for this job which discussed with the table below.

Table 1: - Comparison in between the Sensors

\begin{tabular}{|c|c|c|}
\hline Parameters & IR Sensor & $\begin{array}{c}\text { Ultrasonic } \\
\text { Sensor }\end{array}$ \\
\hline Range & $10 \mathrm{~cm}-80 \mathrm{~cm}$ & $2 \mathrm{~cm}-10 \mathrm{~cm}$ \\
\hline Beam - Width & $75 \mathrm{Deg}$. & 30 Deg. \\
\hline Beam - Pattern & Narrow (Line) & Conical \\
\hline Frequency & $353 \mathrm{THz}$ & $40 \mathrm{KHz}$ \\
\hline Unit Cost & $750 \mathrm{INR}$ & $130 \mathrm{INR}$ \\
\hline
\end{tabular}

The Table 1 shows how a Ultrasonic sensor is more suitable for the System because the range is small to that of the IR Sensor which is quite large which occupies more space in the parking lot which is left wasted and also no one should be allowed in the large space because the object detection will get triggered. This is not the case for the Ultra sonic sensors with small range fitting for a parking slot in the parking space and has a conical beam to detect within that conical space rather than a narrow streamline wave. Moreover, each unit cost for the sensors is significantly low and therefore better component overall for this System

- Real Time tracking is shown with the help of graphs for each slot to keep a track of all the parking slots

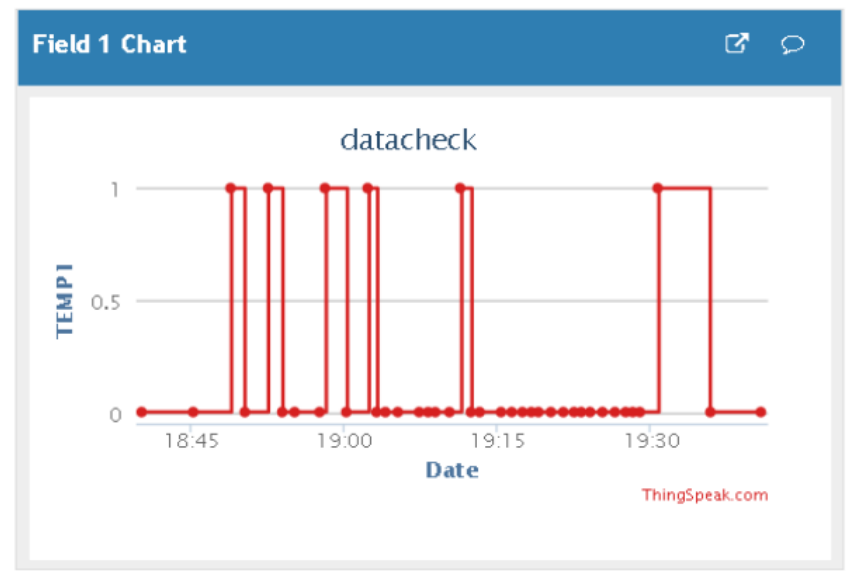

Figure 4: - Graph to show tracking of the Slot 1 in the Parking Space

The Figure 4 is a Graph which is made using ThingSpeak which shows a detailed tracking of a parking slot with the time at which the parking space was occupied and the time at which it was left free. This helps to keep a track of each slot and faults in the object detection system can be easily monitored and rectified. This is quite handy because in ideal scenarios it is quite difficult to track the faults in the System, with this API it enables to repair the system easily

- The most effective way of Parking Technology used is a Computer-View based Technology.

There are various types of Parking Technologies used and if we conduct a survey of what all technologies are used at random, the Figure 5 displays what all Technologies for a random 50 Parking Lots. This shows that Agent based is the most popular with the GPS Based also with more count, these forms of technologies are primitive and most generally followed by the people. These are not accurate for the user to get his parking space which takes a lot of time for finding the parking space itself by asking the agents again and again or finding the parking in their tiny GPS device.

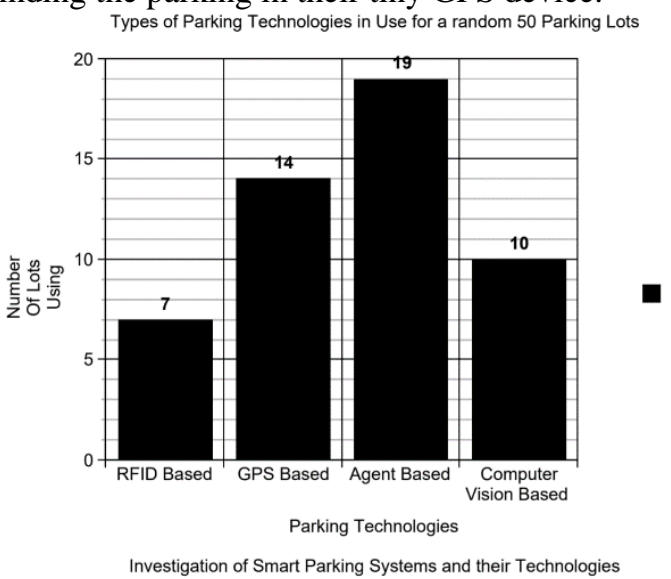

Computer Vison Based is most reliable as it accurately shows where the parking space is located and guides the User to their parking space. This survey states that the Computer Based is better perceived by the people as Visually seeing their parking space is better than getting to loop around for a parking space. A Web Application which is easily available to all is one of the best views to show the people their parking space and this web application is easily scalable to handle multiple users at a time.

\section{CONCLUSION}

The entire base of any System is to be reliable and using simple methodologies and the technologies available to all I can say that this Smart Parking System is reliable and can be implemented in any parking lot. The Prototype of this project is working properly, and the output will be displayed as shown in the above Figures. In this System, the slot detection and updating of data is real time so the users get their parking space as fast as possible. This System is also highly secure with password protection on all your sessions in the portal with regular check of the vacant slot detection every 5 minutes. The data obtained gets stored in a real time database, whose history can be used for further enhancing of the System for that Parking Space. This proposed system we designed a system which allows the end customer to find an unoccupied place in the parking area, the path to that unoccupied place is displayed to the user so that he can park their car in minimal amount of time. This system can be used in many places like offices, malls, townships, etc. The vacant slot is detected first using ultrasonic sensors, and then it gets passed to microcontroller which moves the data to the cloud, from there it is captured and displayed in the form of a web application.

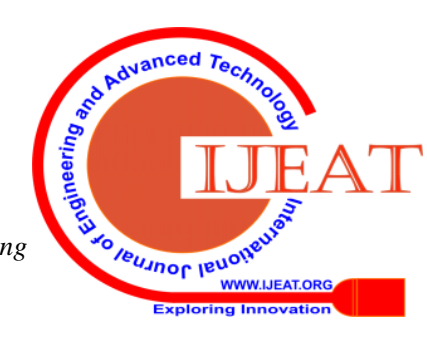




\section{REFERENCES}

1. Alam, M., Moroni, D., Pieri, G., Tampucci, M., Gomes, M., Fonseca, J., Ferreira, J., 1, and Leone, G. R. (2018). "Real-time smart parking systems integration in distributed ITS for smart cities." 2018, 1-13.

2. Bachhav, J. D. and Prof. Mechkul, M. (2017). "Smart car parking system." International Research Journal of Engineering and Technology (IRJET), Vol. 04. 3036-3038.

3. Basavaraju, S. R. (2015). "Automatic smart parking system using internet of things." International Journal of Scientific and Research Publications (IJSRP), Vol. 5. 629-632.

4. Fraifer, Muftah \& Fernström, Mikael. (2016). Investigation of Smart Parking Systems and their technologies.

5. Ghosh, S., Prusty, S., and Natarajan, P. B. (2018). "Design and implementation of smart car parking system using labview.' International Journal of Pure and Applied Mathematics, 120, 329-338

6. Huq Osmani Ahteshamul, M. N. A. G. and Wavre, S. (2016). "Reasearch paper on smartcity parking system." International Journal of Advance Research and Innovative Ideas in Education (IJARIIE), Vol. 2. 2998-3000.

7. JOSEPH, J., PATIL, R., NARAHARI, S., DIDAGI, Y., Bapat, J., and Das, D. (2014). "Wireless sensor network based smart parking system." Sensors and Transducers, 162, 5-10.

8. Khanna, A. and Anand, R. (2016). "Iot based smart parking system." 2016 International Conference on Internet of Things and Applications (IOTA). 266-270.

9. Roja, T. V., Sandhya, N., Ashwini, and Harshitha, B. (2018). "Smart parking system using iot." International Journal of Advance Research, Ideas and Innovations in Technology (IJARIIT), Vol. 4. 1932-1934.

10. Saidur Rahman, Poly Bhoumik (2019). IoT Based Smart Parking System International Journal of Advances in Computer and Electronics Engineering Daffodil Institute of IT, Dhaka Bangladesh,

11. Thangam, E. C., Mohan, M., Ganesh, J., and Sukesh, C. V. (2018). "Internet of things (IOT) based smart parking reservation system using raspberry-pi.

\section{AUTHOR PROFILE}

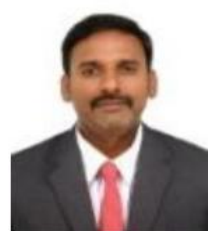

B. Sivakumar received his Bachelor of Engineering degree in Computer Science Engineering in 2000, Master of Engineering Degree in Computer Science Engineering in 2007 and obtained his Ph.D. from Anna University Chennai in the year 2017. His publication includes 9 international journals, 6 international conferences. He is a member of IETE, ISTE. He is currently working as Associate Professor in the Department of Computer Science and Engineering at SRMIST, Kattankulathur, Chennai. He researches interest is Wireless Communication, Big Data and Cloud Computing.

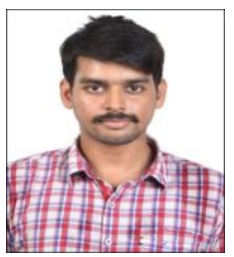

B. Sai Srinivas is currently pursuing his Bachelor of Engineering degree in Computer Science Engineering from 2016 in SRM Institute of Science and Technology, Kattankulathur, Chennai. He has gathered knowledge by working as an intern in companies of Skoda Auto India, Moksha Solutions, Aurangabad and by certified courses in NPTEL on Design and Analysis of Algorithms and Java. He is currently working as a trainee in Bridge Solutions Group India, Bangalore. His research interests are Web Designing, Microservices and Smart Sensor Networks.

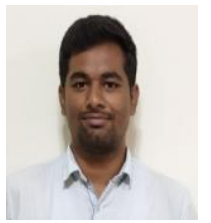

V Ritvik Reddy is currently pursuing his Bachelor of Engineering degree in Computer Science Engineering in SRM Institute of Science and Technology Kattankulathur, Chennai. He has completed certified online courses in NPTEL on Design and Analysis of Algorithms and Cloud Computing. He has recently finished his internship in Infosys. His is interested in Cloud Computing, Smart Sensor Networks.

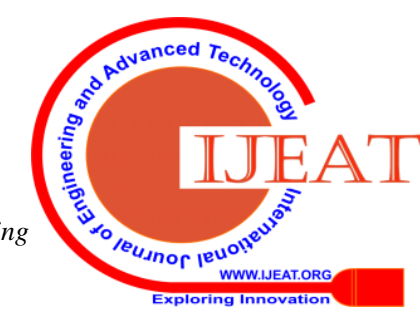

